\title{
CLASSIFICATION OF THE SOCIO-PSYCHOLOGICAL ASPECTS OF PROTECTING SOFT TARGETS: A CASE STUDY FOR EVACUATION OF THE RAILWAY TERMINALS
}

\author{
Alena Šplíchalová1,*, Tomáš Karásek ${ }^{1}$, Tomáš Apeltauer ${ }^{2}$ \\ ${ }^{1}$ Faculty of Social Sciences, Charles University, Prague, Czech Republic \\ ${ }^{2}$ Faculty of Civil Engineering, Brno University of Technology, Brno, Czech Republic \\ *E-mail of corresponding author: alena.splichalova@vsb.cz
}

\section{Resume}

Current crisis management approaches to protect soft targets make assumptions about average visitors/listeners/viewers or passengers. They do not give much consideration to impacts of diversity of potentially evacuated persons with regard to socio-psychological parameters/factors that may lead to practical problems and complications during the evacuation itself. At the same time, the soft target operators have various means of machine vision tools at their disposal, but do not use these records for more thorough analysis of evacuation planning needs. Based on this observation, the article identifies and analyzes the socio-psychological aspects that may significantly affect behavior and decisions of persons during the evacuation and thus total evacuation time.

Available online: https://doi.org/10.26552/com.C.2021.3.F71-F82

\section{Article info}

Received 18 September 2020

Accepted 24 November 2020

Online 30 March 2021

\section{Keywords:}

evacuation, socio-psychological aspects, protection of soft targets, station terminal, bomb threat

\section{Introduction}

Protection of persons, which temporarily are using certain public buildings or spaces, i.e. soft targets, are protected through the preventative measures, e.g. systems of physical protection, passive barriers, etc. These measures prevent emergency events from occurring within infrastructure and public spaces. That is why they must be kept fully functional and up-to-date, especially through the integration of dynamic parameters, application of newly obtained knowledge [1] or systematic searches and rectification of any shortcomings [2]. This knowledge can then be implemented and used for crisis management information systems [3], which will ensure timely and effective protection of individuals. Once these systems are disrupted or fail, then it is necessary to resort to other means to protect the populace, i.e. to evacuate them from places affected by emergency events.

One of the basic tasks of population protection is to evacuate people during emergencies and to ensure their subsequent shelter and emergency survival. As an organizational measure subject to legal regulations and technical standards, evacuations ensure the timely response of a population to a threat or emergency event, minimizing loss of life and injuries [4]. An evacuation consists of a set of activities ensuring the relocation of persons in a given order, according, to priority from places threatened by an emergency event to predetermined safe places [5]. The ability to safely evacuate and effective calculate the number of people evacuated is essential for planning, designing and subsequently operating infrastructure [6]. Of course, in practice one finds that the measures currently required by law do not always provide the support that people need in buildings during an emergency event [7].

Large railway stations with complicated architecture are common in today's integrated railway networks. In this transportation infrastructure, evacuation plans are commonly designed using timeline analysis comparing Available Safe Egress Time (ASET) and Required Safe Egress Time (RSET) with approved scenarios. This approach, however, does not take much account of a basic variable, which is the behavior and decision-making of people during the evacuation itself and likewise, directly before it. In recent years, research has been conducted into human behavior during evacuations [8-9] and the results have been applied to sophisticated computer systems. However, this research was conducted on a sample of mostly healthy people that did not reflect a diverse composition of people.

ASET/RSET timeline analysis was developed over 30 years ago and therefore should be revised to apply to the extensive and structurally complicated infrastructure 


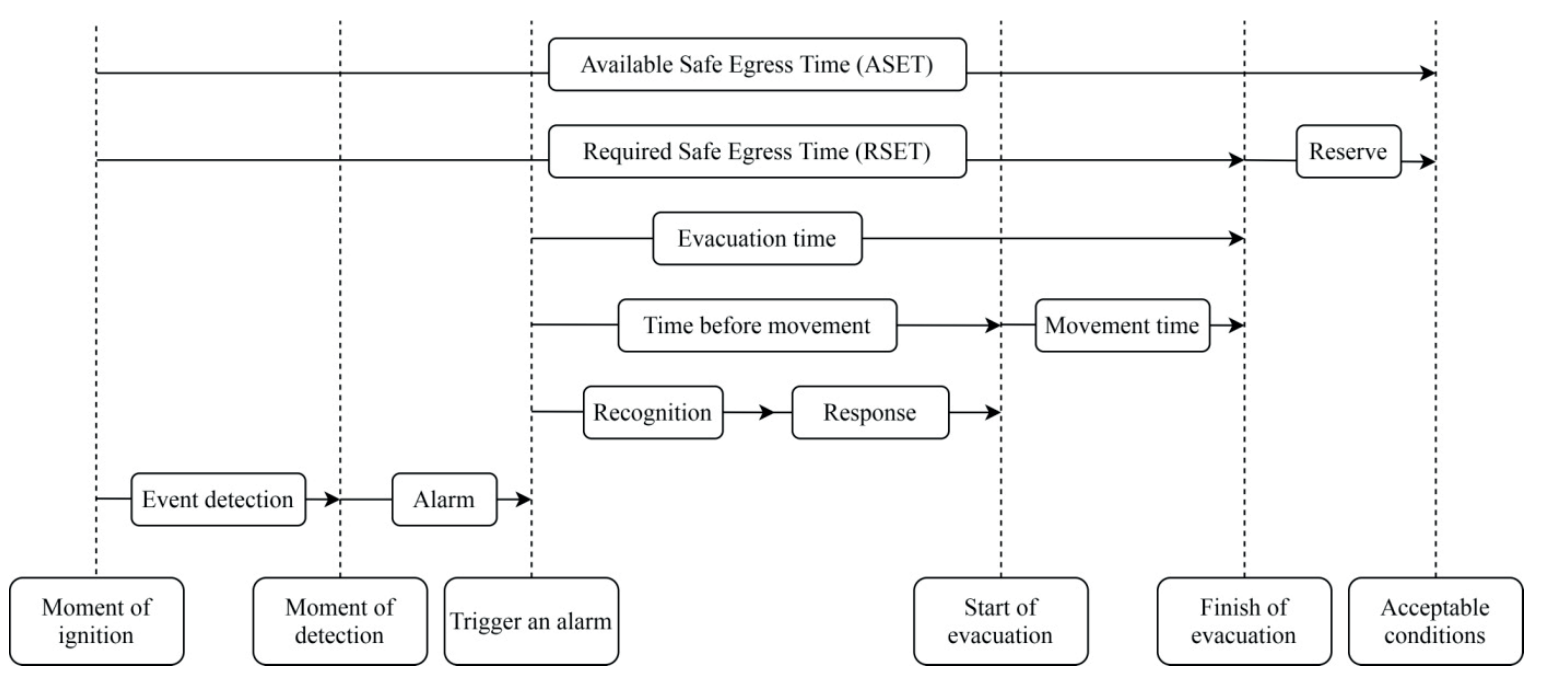

Figure 1 Relationship between individual components of the evacuation process and its length [13]

of today [10]. One of the ways it can be updated is to incorporate the heterogeneous behavior of persons so that models not only consider the response of healthy people, but especially people with limited orientation and movement and seniors, who fundamentally affect evacuation time. Likewise, psychonomy also has a significant impact on the behavior or people when responding to an emergency [7]. Based on these facts, the current conventional approach to calculating evacuation time must be augmented with scientific knowledge in this area.

In the context of the above, the goal was to define factors affecting the total evacuation time according to the well-known ASET/RSET approach and then point out the possible gaps, deviations or shortcomings of this approach that fundamentally impact the total evacuation time. Particular attention was given to the socio-psychological aspects of the evacuated persons and their impact on the total evacuation time.

\section{Technical factors determining evacuation time (ASET/RSET)}

The safety of visitors and people in buildings is defined by an evaluation based on a set of acceptance criteria. These criteria are to a considerable degree expressed by occupancy limits of visitors who may potentially be exposed to the effects of an emergency [11]. Safety during an emergency event is ensured by evacuation, where the decisive factor is the amount of time left to safely exit (time to unsustainable conditions) and the amount of time required to safely exit (building evacuation time). The basic concept when evaluating the safety of people in a building is to determine the time required for people to escape safely from the space and pass-through escape routes to a safe place before the conditions that endanger their health and lives occur [12]. This is calculated through ASET/RSET methods that determine the safety of travelers. It is a simple time- based approach where both parameters are dependent on several variables that follow from the nature of the emergency event, the character of the building and the composition and behavior of the persons evacuated. An assessment of the safe exit time is fundamental for organizing the evacuation of people in buildings, structures, or generally enclosed spaces [13].

A basic approach when analyzing effectiveness of an evacuation itself is the location and movement of people in the space examined [14]. The requirement of the safe exit and sufficient protection is defined as the difference between Available Safe Egress Time (ASET) and Required Safe Egress Time (RSET). This ratio must always be maintained, i.e. RSET < ASET. If this condition is met, the safe exit of persons is completed before conditions become dangerous [15].

The ASET, or the time for which safe conditions for travelers are guaranteed, is generally assessed using analytical equations or models simulating adverse events. In the event of a fire, it is suitable for preliminary and routine risk assessment of an adverse event due to its simple and rapid use [16]. It is determined from the moment when the effects of the emergency event reach the thresholds prescribed in the acceptance criteria. In contrast, the RSET is a variable based on an analysis of the time required by travelers to safely escape the impacts of the emergency event [11]. The RSET is often estimated on a simple technical level, taking little account of factors caused by human behavior. The RSET, or the time required to safely exit, is the sum of time to detect and react to an alarm, plus movement. The relationship between both quantities is shown in Figure 1.

The conventional ASET/RSET approach was founded on the simple concept of a two-layer zone model [17]. This model only expresses the period of unsustainable conditions for individual rooms and the evacuation time is evaluated in the same way. Nevertheless, this approach is still used today for much larger and more complicated building complexes without the slightest modification, even though the adequacy 
of this approach is only occasionally discussed and not addressed in detail [11]. Since the inception of the ASET/RSET approach, a number of more sophisticated calculations methods have appeared that go beyond the framework of basic calculations. Today, complicated computer modelling of evacuation dynamics has become an integral component of simulation models and not only in a two-dimensional representation. These models also incorporate other factors affecting the RSET such as distance, overcrowding, visibility, proximity of exits to their destination or distribution of exits [18]. The concept for calculating the ASET/RSET, however, has not been adapted to this development. Continued use of the current ASET/RSET approach under these conditions could lead to significant shortcomings and inaccurate calculations, which would lead to deviations from the intended scope of purpose of providing a basic benchmark for assessing exit safety, originally proposed by Cooper [11].

For example, in the area of the fire safety, according to Babrauska et al. [19], the ASET/RSET concept is considered intrinsically defective and its use reduces the fire safety of travelers in a building. According to the authors, the concept ignores any differences in the physical abilities and condition of the people being evacuated and takes a robot-like approach to people's decision making. In the overwhelming majority of cases, evacuation time is influenced by the composition of people, their decision-making, the social relationships between them, injured people etc. These additional aspects of evacuation are considered in the computer tools already mentioned. In most cases, these tools consider the nature of the space, individual attributes, the distribution of emergency exits and possible loss of route due to the incident. These models may also include factors that significantly affect the behavior of people and their decision-making process. However, if such factors are included at all, they are very general and behavior of the people being evacuated is oversimplified [20]. Knowledge regarding the behavior of people during an evacuation and their response to emergency events is limited regardless of approach. This shortcoming stems from the lack of a comprehensive conceptual model for the decision-making and behavior of evacuees during the emergency event [12]. There is also little literature available on viable alternatives to this simplified manner of evaluating the safe escape [11].

The literature also mentions possible modifications and adaptations of the current approach. One possibility is a simple revision, consisting in the modification of the ASET to ASUT, i.e. the available time that an area can be safely used for escape and RSUT, the required time for safely using an area for escape [11]. This change considers the longest possible duration of the evacuation itself, the time when an area is last used by an occupant. This simple revision enables designers to take into consideration detailed information from more advanced simulation models. Similarly, Schroder et al. [21] consider use of the ASET/RSET ambiguous and therefore propose a map representation of this approach. The maps are generated by spatial evaluation of quantities, yielding a difference map representing safety reserve. This approach helps to determine the evacuation time in multi-dimensional or risk-based analyses. Another person taking an innovative approach to the ASET/RSET was Sime [22], who in his work began to combine and unify aspects of psychology, architecture, engineering and facility management through the concepts of occupancy, occupants and passenger location. Another modification, the primary goal of which is to bridge the divide between psychology and engineering, is occupant response shelter escape time (ORSET).

The aforementioned modifications of the ASET/ RSET approach can decrease uncertainty in a design based solely on performance. It has been shown that such an approach is insufficient and it is therefore necessary to focus the future research on the aspects that significantly affect evacuation time. The most important aspects, contributing to major deviations from the planned evacuation time, are composition of the evacuees, their human behavior, response time and decision-making.

\section{Socio-psychological aspects of evacuation}

As already mentioned above, the process of evacuation is characterized by technical factors such as spatial requirements (i.e. width, length of narrow places, number of escape routes, etc.) and the related speed of people's movement. It is also important when calculating the RSET to include person-related factors (i.e. individual physical condition, age, mental state etc.), their geometry, as well as required assistance or orientational ability [23]. The aforementioned aspects have a fundamental impact on the movement behavior of evacuees.

Another important group of factors affecting the RSET are the socio-psychological aspects. In current models these aspects are taken into account too generally and, in most cases, homogeneously, if they are taken into account at all. Very rarely are evacuees viewed as a heterogenous group of persons, capable of making different decisions based on perception of the environment and individual personal characteristics. It follows from the above that evacuation models do not take into consideration the variability of evacuee composition and therefore do not take into account possible delays in the response time. Based on this fact, social psychology has gradually been applied to the process of calculating evacuation time, since human behavior during this phase is an important factor from a survival perspective [7].

The social psychology is one of the basic psychological disciplines that strives to understand and also explain the thought and behavior of individuals influenced by the actual, perceived or anticipated presence of 
Table 1 Three components for the fire response performance model [7]

\begin{tabular}{lll}
\hline human features & building features & fire features \\
\hline individual features & engineered features & perceptual features \\
- personality & - lay out & - visual features \\
- knowledge \& experience & - installations & - smelling features \\
- powers of observation & - materials & - audible features \\
- powers of judgement & - compartments & - tangible features \\
- powers of movement & - size of building & \\
\hline social features & situational features & fire growth rate \\
- affiliation (e.g. family) & - focus point & smoke yield \\
- task fixation & - occupant density & toxicity \\
- role/responsibility & - ease of way finding & heat \\
& - building evacuation team & \\
\hline situational features & - maintenance & \\
- awareness & & \\
- physical position & & \\
\hline
\end{tabular}

others. Social psychology deals with behavior of an individual in a social environment. This discipline can also be understood as the study of individuals in their interactions with others and the interplay of individual thoughts, feelings, emotions and habits [24]. Social psychology thus examines the question to what degree the behavior of an individual is influenced by behavior of others (relatives, society, groups of people, etc.), meaning that it examines the behavior of individuals with respect to social stimuli in the surroundings [25-26], whether individuals become members of a social group and how they function in these groups. This is therefore an interdisciplinary understanding that derives the laws, development, changes and nature of interpersonal behavior. Social psychology can be defined as the actions people take based on their perception of a situation, their intention to act and considerations ensuing from crowd behavior [7].

Scientific research into human behavior during the adverse events is relatively new. Since the beginning of the $20^{\text {th }}$ century there have been a number of monitored evacuation studies along with investigations of catastrophes in various types of infrastructure [18, 27-28]. Many studies have also been carried out [7, 29-31] showing that the sociological and psychological aspects of human behavior significantly affect the time required for evacuation. These studies have also confirmed an interaction between evacuees, buildings and the course of various emergencies. These three components are presented in Table 1 for the case of a fire.

Kobes [7] defines three component areas that have a fundamental impact on the RSET. The first is human features, which have a direct and primary effect on the level of response to an emergency event and are examined from the perspective of both individuals (individual characteristics) and groups (social and situational characteristics). Another major component is building features, which define the evacuated space and provide crucial information for selecting escape routes. The final area is, in this case, fire features. Here, the characteristics and subsequent development of the emergency event are crucial.

\section{Factors influencing the behavior/decision making of people during an evacuation}

Understanding the human behavior and decision making during the evacuation process becomes an important aspect of increasing infrastructure safety and ensuring the reliable movement of people. The very movement of heterogeneous groups of people and their interaction is important to properly design buildings and reasonably predict the course of an evacuation [32]. Empirical data on behavior during an evacuation, its effectiveness and the spread of an emergency event is scarce. There are numerical simulations to determine available and required safe exit periods [33-37], however, these are founded on imprecise homogeneous data and ideal groups of individuals. For these reasons, it is necessary to devote increased attention primarily to those factors that significantly affect the behavior and decision-making of people during the evacuation period.

People's behavior is the result of their perception, interpretation and decision-making process, which is influenced by external and internal factors [3839]. External factors or factors that characterize and shape the building environment (for example, type of a building, number, location and width of emergency exits, location of stairways, application of evacuation signs, bottlenecks, etc.) only affect human behavior to a certain degree. However, internal factors, i.e. human characteristics, are considered as the key factors that determine response to the effects of emergency 
events [36]. Kobes [7] claims that individual, social and situational traits are critical, while individual elements can further be broken down into physiological and psychological characteristics [6]. Most authors agree that human characteristics significantly affect people's behavior and have a more significant impact on people's decision making than external factors. For this reason, the following text is devoted only to internal or sociopsychological factors.

\subsection{Physiological individual traits}

The socio-psychological aspects affect people's decision-making, their search and selection of evacuation routes, the speed and movement of evacuees and fundamentally also affect the RSET. These aspects are characterized by the individual abilities of individuals in combination with the environment in which they find themselves. Important individual physiological characteristics include the composition of people in the evacuation space, their roles, age, gender, mental capacity and body weight. The evacuation time is also influenced by crowd density and percentage of people unable to find an escape route without assistance, presence of people with strollers, etc. [6, 22-23, 32, 40].

\subsection{Psychological individual traits}

The psychological characteristics of people are also important. These factors include people's cognitive and emotional states. Severe stress or, conversely, refusal to acknowledge the life-threatening events, prevents effective evacuation. Likewise, inaction, apathy or children dependent on other people prevent survivors from evacuating [6, 41]. The relationship between the speed of movement and emotional state has been derived using a theory of extreme values [42]. One must also not to forget the specific characteristics of individuals, which include [43]:

- Instincts - Instincts influence the innate pattern of behavioral response to certain stimuli. A person can act instinctively without even being aware of it. When under the great stress, people tend to follow their instincts as the most primitive response when making split second decisions.

- Experience - Based on previous situations (knowledge of safety procedures, fire safety training, etc.), it is possible to derive a relatively standard routine and then apply it to situations in the future.

- Limited rationality - This assumes decision-making based on evaluation of the alternatives in terms of their implications for preferences, i.e. searching for possibilities; anticipation of consequences; consideration of each consequence with respect to preferences and selection of the most appropriate option.
A relationship between intelligence and evacuation success was also confirmed and it was shown that specific personal characteristics tend to have a small effect on evacuation efficiency. In contrast, psychological states (anxiety, depression, stress, etc.) have a large negative impact on cognitive function, which is essential for an effective evacuation [41]. The field that deals with discovering the laws governing human behavior is psychometry [44]. Three personal traits in particular are important in this approach [7]:

- Leader/follower (active/passive) - This personal trait is very important. Most people during evacuations are followers who do not react to danger signals, but rather wait on others before they start to act. To the contrary, a leader in stress situations is able to make effective decisions. In most cases, leaders are the people who are organizationally responsible for the building based on their roles or positions.

- Resistance to stress - too much physical stress leads can overload one's capacity for processing information and can disrupt cognitive processes (as an individual reacts to the given situation) [45].

- Belief in self-efficacy - to what degree does a given person believe in himself or herself? This affects the efforts they make and the time required to act if they encounter an obstacle.

\subsection{Social traits}

Actions and decision-making are very strongly influenced by the social bonds existing between individual persons that create groups and shape interpersonal distance. These ties have a significant impact on behavior of the groups formed, which tend to move in mutual agreement and leave areas together [43]. Decisive social characteristics include interaction between the people present, the degree to which tasks are performed and the role of people in the building. In most cases, people tend to work together and respond as a group for as long as possible instead of acting individually. This fact is enhanced if strong social bonds exist between people (family, partners) [7]. All of these aspects impact the course of the evacuation, the response time and decisionmaking. If people become separated from each other, e.g. a family, this fact can lead to opposing movement and prevent the flow of the crowd as a whole, which may disrupt the permeability of emergency exits [43]. People who are part of a group tend not to make decisions for themselves, but rather wait on the response and decision of others [46]. This fact is supported by the generally accepted notion that an individual in a crowd usually acts differently than when alone [47].

\subsection{Situational traits}

The last group of factors that influence the behavior of people is associated with situational characteristics 
Table 2 Impact of the socio-psychological aspects on RSET

\begin{tabular}{|c|c|c|c|c|}
\hline \multirow{2}{*}{\multicolumn{2}{|c|}{ socio-psychological aspects }} & \multicolumn{3}{|c|}{ components of the RSET evacuation process } \\
\hline & & recognition time & response time & movement time \\
\hline \multirow{4}{*}{$\begin{array}{l}\text { individual physiological } \\
\text { traits }\end{array}$} & role & $\mathrm{X}$ & $\mathrm{X}$ & \\
\hline & age & $\mathrm{X}$ & & $\mathrm{X}$ \\
\hline & cognitive ability & & $\mathrm{X}$ & \\
\hline & body weight & & & $\mathrm{X}$ \\
\hline \multirow{6}{*}{$\begin{array}{l}\text { individual psychological } \\
\text { traits }\end{array}$} & instinct & $\mathrm{X}$ & $\mathrm{X}$ & \\
\hline & experience & $\mathrm{X}$ & & $\mathrm{X}$ \\
\hline & limited rationality & & $\mathrm{X}$ & $\mathrm{X}$ \\
\hline & emotional state /resistance to stress & & $\mathrm{X}$ & $\mathrm{X}$ \\
\hline & leader/follower & $\mathrm{X}$ & $\mathrm{X}$ & $\mathrm{X}$ \\
\hline & belief in self-efficacy & & & $\mathrm{X}$ \\
\hline \multirow{2}{*}{ social traits } & interpersonal distance & & $\mathrm{X}$ & \\
\hline & strength of social bonds & $\mathrm{X}$ & $\mathrm{X}$ & $\mathrm{X}$ \\
\hline \multirow{3}{*}{ situational traits } & awareness of emergency & $\mathrm{X}$ & $\mathrm{X}$ & \\
\hline & physical position of person & & $\mathrm{X}$ & $\mathrm{X}$ \\
\hline & knowledge of building layout & & $\mathrm{X}$ & $\mathrm{X}$ \\
\hline
\end{tabular}

including awareness, physical location and knowledge of the building layout [7]. Awareness of an adverse event means certain knowledge about the possible course of the emergency or how it would tend to develop. It is important to mention that awareness is dependent on the alertness of people, which may be reduced by fatigue or consumption of alcohol or narcotics [48]. Physical position means the present position of a person (standing, walking, sitting or lying). The layout of the building and especially knowledge of the layout significantly affects decisions on selecting evacuation routes. Analysis of observed phenomena clearly shows that most people leave buildings along the route they know (usually the main entrance) and thus ignore alternatives that may be more effective [43].

In addition to the aspects above, Sime [49] considers one of the most important aspects to be occupancy, which defines the relationship between people and the environment. This is based on research on human behavior during emergencies and evacuations and research in environmental behavior and environmental psychology. Sime [22] further claims that a person is different in each and every physical (and social) setting and situation. Each person is limited by the conditions and amount of knowledge and action provided by various social, organizational and physical conditions and environments occupied by people over the course of time.

The socio-psychological aspects and behavior of people during evacuation are currently part of most computer programs simulating evacuation conditions in fire safety engineering and crowd safety using the RSET [50-52]. With help of these most advanced, three-dimensional and intelligent computer tools it is possible to predict behavior to a certain degree $[46,53]$. The main limitation of these sophisticated systems is the assumption of homogeneity, which presumes that people will react to specific stimuli in a similar manner [54]. Another limiting factor is the technical data describing the movement characteristics of evacuees. This system input data is generally based on young and healthy populations and often does not take into account indisposed people. Yet, the current composition of the population and demographic trends confirm the growing number of handicapped individuals and older or generally less mobile people [55]. In addition to the effects of aging, these people suffer from impaired perception, reduced information processing and reduced mobility [56]. While technical computer evacuations models do exist to estimate movement times of people and their evacuation behavior, these are poorly described and quantified and adopt simplified behavioral assumptions. Thus, this data is highly unrealistic and can provide inaccurate results [43, 57]. It is necessary to enrich all this data with a population structure that is diverse to yield more accurate calculations and ensure evacuation to a safe place. Based on the above, it is essential to apply the socio-psychological aspects to the process of calculating the total evacuation time, since these aspects have a significant impact on the speed, accuracy, efficiency and effectiveness of decision-making.

\subsection{Influence of the socio-psychological aspects on evacuation time}

It follows from the above that the socio-psychological aspects are a very significant component affecting the reaction time and decision-making process of evacuees, thus affecting the total time required to relocate people to a safe space. Table 2 below presents a qualitative comparison of select psychological aspects 
Table 3 Values of evacuation condition coefficients according to CSN 730802 [62]

\begin{tabular}{lc}
\hline evacuees & unprotected escape route \\
\hline able to move independently & 1.0 \\
with limited mobility & 1.5 \\
unable to move independently & 2.0 \\
\hline
\end{tabular}

Table 4 Calculation of the preliminary evacuation time according to [62]

\begin{tabular}{lc}
\hline parameters of preliminary evacuation time & value of individual parameters \\
\hline length of escape route & $150 \mathrm{~m}$ \\
speed of evacuee movement & $20 \mathrm{~m}^{-m^{-1}}$ \\
number of evacuated persons & 6000 \\
coefficient of evacuation conditions ${ }^{*}$ & 1.25 \\
unit capacity of escape lane & 40 \\
number of escape lanes & 8 \\
estimated evacuation time & $29 \mathrm{~min}^{2}$ \\
\hline
\end{tabular}

* This value was adjusted based on the variability of evacuated persons

that significantly impact components of the RSET evacuation process.

The recognition time can be described as the time it takes for a person/group of persons to identify and assess the severity of an emergency event according to certain features. The response time is the time it takes for people to react to the severity of an emergency event and the related need to take certain steps leading to subsequent evacuation. The movement time is the time it takes for people to move from an evacuation zone to emergency exits and then to the evacuation center. From Table 2 it follows that the socio-psychological aspects have a significant impact on people's decision-making process in all the phases of evacuation and therefore fundamentally affect total evacuation time. Based on a qualitative comparison of individual components it is possible to identify the most important sociopsychological aspects, including the role of leader/ follower and the strength of social bonds. These aspects were then used in the case study.

\section{Case study of application of the socio- psychological aspects during the evacuation of a railway terminal}

To verify the theory based on current data on the socio-psychological aspects and their practical application, a hub in the transportation infrastructure of the Czech Republic was chosen. Since this is a public space with a very high concentration of people during the day and sometimes also at night, the building in question may be considered a soft target. Specifically, it is a soft target in the transportation category and interchange sub-category [58]. This element was chosen based on its significance, scope, purpose, reliability and assessment of its critical nature [58-59]. This element is interconnected with other systems. Its disruption or failure would have serious implications to the system itself and significant consequences to other critical infrastructure sectors [60]. The area selected is one of the busiest railway stations in the Czech Republic, but for reasons of safety remains anonymous. The station handles an average of 70,000 travelers a day [61]. The complex is quite extensive, consisting of platforms, passages, underground and above-ground floors, stores, restaurants, a concourse and passenger service areas. Given this fact, in this case study the focus was only on the concourse building consisting of one above-ground floor and three underground floors.

In the building there are several contract carriers along with a large number of shops. There are also restaurants, fast food, grocery stores, bookstores, information booths, clothing stores and other passenger services. Travelers not only use this space to access platforms but they also wait here for trains to arrive and depart. Because of this, a large number of people are often gathered here, which is one of the reasons why this building in particular was selected. It is a location with large groups of people and the probability of an attack is greater here [58]. The case study examines the evacuation of the main station due to a violent attack, specifically, a booby-trapped explosive device placed in the station. According to the risk analysis performed [58], this threat is classified as a secondarily significant risk and security against this type of emergency is low.

The anticipated evacuation time is calculated according to Formula 1, where the value for $s$ only represents the values of coefficients determined according to standards [62] and does not reflect the socio-psychological aspects:

$t_{u}=\frac{0.75 \cdot l_{u}}{v_{u}}+\frac{E \cdot s}{K_{u} \cdot u}$,

where: $t_{u}=$ estimated evacuation time; $l_{u}=$ length 
of escape route; $v_{u}=$ speed of evacuee movement; $E=$ number of persons evacuated; $s=$ evacuation conditions coefficient; $K_{u}=$ unit capacity of escape lane; $u=$ number of escape lanes.

These calculations include only the minimal physiological aspects of the persons evacuated, such as able-bodied individuals, persons with reduced mobility or persons unable to move independently. This calculation approach also does not consider the specifics of individuals (i.e. passengers, employees, passenger escorts, etc.), their percentage representation in the total number of evacuees and psychological or social traits. These aspects, however, do affect the total evacuation time.

For calculations were used the coefficient input values given in Table 3 , which are set out in CSN 730802 [62]. Table 4 then presents values needed to calculate the preliminary evacuation time according to current standards [62].

The simplified calculation of evacuation time carried out is merely an illustrative estimate of anticipated evacuation time. Fictitious values were used in this calculation. The subsequent evacuation time was calculated to be 29 minutes, although this does not include the socio-psychological aspects that enter into all the phases of evacuation (recognition, response and movement time). Based on a survey of the literature, it is presumed that that the inclusion of these aspects would increase the evacuation time. This fact is mainly due to the coefficient of evacuation conditions, which, however, currently only reflects the ability of evacuees to move independently (see Table 3).

In the context of currently identified sociopsychological aspects (see Table 2), the factors determining the coefficient of evacuation conditions are expanded in the following manner:

$s=f\left(s_{s p o} ; s_{f y z} ; s_{p s y} ; s_{s o c} ; s_{s i t}\right)$,

where: $s_{s p o}=$ ability of people to move; $s_{f y z}=$ physiological traits; $s_{p s y}=$ psychological traits; $s_{s o c}=$ social traits; $s_{s i t}=$ situational traits.

The basic parameter $s$ is logically expanded by four variables, i.e. the socio-psychological aspects, affecting evacuation time. The current value of the coefficient of evacuation conditions (see Table 3) is retained, although its impact on the total value of the parameter is considerably lower. The percentage share of the proposed parameters cannot be clearly defined under the current conditions, especially due to a lack of professional studies on human behavior during evacuation. At present, studies do exist showing that individual aspects impact evacuation time, e.g. it has been demonstrated that up to $73 \%$ of people evacuate with one or more member of a group and $80 \%$ of these are family members [63]. Nevertheless, this and similar research does not determine the significance or mutual comparison of individual aspects. This fact represents a gap in research that must be addressed in the future.

Another condition that must be met by parameter $s$ is its total value, which lies within a closed interval of $<1,2>$ but must not exceed the upper limit of two. This value represents the movement time of people incapable of independent movement, i.e. double the evacuation time of people capable of independent movement, that is set by the standard [62]. When maintaining the parameters of Table 4 and setting the highest possible values for the coefficient of evacuation conditions, it can be concluded that the estimated evacuation time should not be more than 43 minutes. The time difference between calculations $(29,43)$, represents the increase in evacuation time after expanding parameter $s$. These 14 minutes represents the variability and percentage share of the socio-psychological aspects.

\section{Conclusion}

Evacuation is the primary way of protecting soft targets and other types of buildings (e.g. structures and property used for education, social care, health care, culture, public administration, public safety etc.) [64-65], and above all the people inside them in the event of an emergency event [66]. The correct and accurate estimation of evacuation time is essential for ensuring the relocation of people to a safe place in the life-threatening and dangerous conditions. This fact is also the primary challenge for researchers developing evacuation simulations and people responsible for building and operating infrastructure.

The time interval for determining the total evacuation time is commonly determined according to the formula for calculating the RSET. Although this tool has been used for many years, under current conditions it is ineffective due to major shortcomings. Estimated evacuation time calculated according to this approach does not reflect the human factors that enter into the evacuation process. These socio-psychological aspects of human behavior and subsequent decision-making significantly affect the time required to evacuate people. This claim is backed by experimental and post-incident studies that imply patterns of human behavior. Research has shown, however, that these formulas are generally obtained from homogeneous groups of people that are not variable and do not reflect the actual composition of the populace. In this context, it is necessary to focus research on the diverse composition of the population and examine the specifics of people unable to move without assistance, people with limited mobility, senior citizens, etc.

The article also presents a source of information, systematically performed research analysis that serves as a basis for further development of simulation tools necessary to determine the total evacuation time. This article points out the shortcomings of using the current calculation approach according to the RSET and the need to update it. The current calculation 
process must also incorporate the socio-psychological aspects affecting the behavior and decision-making of people. Based on the above, it is necessary to address this issue and develop a complete and comprehensive conceptual model of human behavior and decisionmaking during evacuations. This model would have a major impact on training and education and would also enable complete behavioral patterns of behavior to be incorporated into the simulation tools. In the future, it would also be desirable to create a better methodology or incorporate artificial intelligence and machine vision in the evacuation calculation process, making it possible to obtain the real-time evacuation estimates. The systems developed should use measurements and data based on knowledge of psychological methodology and mathematical statistics to maximize their predictive power. In the context of the above, classification of the socio-psychological aspects is an important input variable for the further development of tools and optimization of evacuation procedures.

\section{Acknowledgments}

This work was supported by the Technology Agency of the Czech Republic [grant number TL02000352].

\section{Reference}

[1] REHAK, D., SENOVSKY, P., HROMADA, M., LOVECEK, T., NOVOTNY, P., Cascading impact assessment in a critical infrastructure system. International Journal of Critical Infrastructure Protection [online]. 2020, 30, p. 125-138 [accessed 2020-10-11]. ISSN 1874-5482. Available from: https://doi.org/10.1016/j.ijcip.2018.06.004

[2] RISTVEJ, J., ONDREJKA, R., SIMAK, L., LOVECEK, T., HOLLA, K., LACINAK, M., SURINOVA, L., JANOSIKOVA, M., Simulation technologies in risk prevention within crisis management. In: 30th European Simulation and Modeling Conference ESM 2016: proceedings. Vol. 2016. ISBN 978-907738195-3.

[3] VICHOVA, K., HROMADA, M., REHAK, D. The use of crisis management information systems in rescue operations of fire rescue service of the Czech Republic. Procedia Engineering [online]. 2017, 192, p. 947-952 [accessed 2020-10-11]. ISSN 1877-7058. Available from: https://doi.org/10.1016/j.proeng.2017.06.163

[4] JAKUBCOVA, L., URBAN, R., KOMASOVA, S., BRICHCIN, P. Crisis management and psychology of evacuees: parameters for streamlining evacuation planning for soft target operators (in Czech). Security Theory and Practice [online]. 2020, 1(2020), p. 3-34 [accessed 2020-10-11]. ISSN 1801-8211, eISSN 2571-4589. Available from: https://veda.polac.cz/?page_id=6004

[5] Decree of the Ministry of the Interior 380 of 22 August 2002 on the preparation and implementation of tasks for the protection of the population (in Czech).

[6] CHEN, S., DI Y., LIU S, WANG, B. Modelling and analysis on emergency evacuation from metro stations. Mathematical Problems in Engineering [online]. 2017, 2623684 [accessed 2020-10-11]. ISSN 1024-123X, eISSN 1563-5147. Available from: https://doi.org/10.1155/2017/2623684

[7] KOBES, M., HELSLOOT, I., DE VRIES, B., JOS G.P. Building safety and human behaviour in fire: a literature review. Fire Safety Journal [online]. 2010, 45(1), p. 1-11 [accessed 2020-10-11]. ISSN 0379-7112. Available from: https://doi.org/10.1016/j.firesaf.2009.08.005

[8] ZHANG, J., SEYFRIED, A. Quantification of bottleneck effects for different types of facilities. Transportation Research Procedia [online]. 2014, 2, p. 51-59 [accessed 2020-10-11]. ISSN 2352-1465. Available from: https://doi.org/10.1016/j.trpro.2014.09.008

[9] GEOERG, P., SCHUMANN, J., BOLTES, M., HOLL, S., HORMANN, A. The influence of physical and mental constraints to a stream of people through a bottleneck. Collective Dynamics [online]. 2020, 5(2020), p. 246-252 [accessed 2020-10-11]. ISSN 2366-8539. Available from: http://dx.doi.org/10.17815/CD.2020.57

[10] KU, Y.C., CHOW, W.K, YUE, T.K. Fire evacuation in a large railway interchange station. In: 11th AsiaOceania Symposium on Fire Science and Technology: proceedings [online]. Singapore: Springer, 2018. ISBN 978-981-32-9139-3. Available from: https://doi.org/10.1007/978-981-32-9139-3_18

[11] POON, S. L. A Dynamic approach to ASET/RSET assessment in performance based design. Procedia Engineering [online]. 2014, 71(2014), p. 173-181 [accessed 2020-10-11]. ISSN 1877-7058. Available from: https://doi.org/10.1016/j.proeng.2014.04.025

[12] KULIGOWSKI, E. D., GWYNNE, S. M., KINSEY, M. J., HULSE, L. Guidance for the model user on representing human behavior in egress models. Fire Technology [online]. 2017, 53(2), p. 649-672. [accessed 2020-10-11]. ISSN 0015-2684, eISSN A1572-8099. Available from: https://doi.org/10.1007/s10694-016-0586-2

[13] TOSOLINI, E., GRIMAZ, S., PECILE, L.C., SALZANO, E. People evacuation: simplified evaluation of available safe egress time (ASET) in enclosures. Chemical Engineering Transactions [online]. 2012, 26, p. 501-506. [accessed 2020-10-11]. ISSN 1974-9791. Available from: https://doi.org/10.3303/CET1226084 
[14] APELTAUER, T., BENES, P., VRANA, L. Application of advanced models of human movement and fire dynamics for safe evacuation of people and risk analysis (in Czech) [online] [accessed 2020-10-11]. 2015. Available from: https://www.profesis.cz/files/dokumpdf/ruzne/r7-2metodikapdf.pdf

[15] FORELL, B., KLUPFEL, H., SCHNEIDER, V., SCHELTER, S. Comparison of evacuation simulation models Aseri, building Exodus, FDS+Evac and PedGo applied to an auditorium. In: Pedestrian and Evacuation Dynamics: proceedings [online] [accessed 2020-10-11]. 2012. Available from: https://doi.org/10.13140/2.1.5156.6725

[16] TOSOLINI, E., GRIMAZ, S., SALZANO, E. A Sensitivity analysis of available safe egress time correlation. Chemical Engineering Transactions [online]. 2013, 31, p. 223-228 [accessed 2020-10-11]. ISSN 1974-9791. Available from: https://doi.org/10.3303/CET1331038

[17] COOPER, L. Y. A concept for estimating available safe egress time in fires. Fire Safety Journal [online]. 1983, 5(2), p. 135-144 [accessed 2020-10-11]. ISSN 0379-7112. Available from: https://doi.org/10.1016/03797112(83)90006-1

[18] HAGHANI, M., SARVI, M. Human exit choice in crowded built environments: Investigating underlying behavioural differences between normal egress and emergency evacuations. Fire Safety Journal [online]. 2016, 85, p. 1-9 [accessed 2020-10-11]. ISSN 0379-7112. Available from: https://doi.org/10.1016/j.firesaf.2016.07.003

[19] BABRAUSKAS, V., FLEMING, J. M., RUSSELL, D. B. RSET/ASET, a flawed concept for fire safety assessment. Fire and Materials [online]. 2010, 34(7), p. 341-355 [accessed 2020-11-10]. ISSN 1099-1018. Available from: https://doi.org/10.1002/fam.1025

[20] GWYNNE, S. N. V. Translating behavioural theory of human response into modelling practice. Technical report [online] [accessed 2020-10-11]. 2012. Available from: https://sapps.nist.gov/publication/get_pdf.cfm?pub_ id $=912794$

[21] SCHRODER, B., ARNOLD, L., SEYFRIED, A. A map representation of the ASET-RSET concept. Fire Safety Journal [online]. 2020, 115, 103154 [accessed 2020-10-11]. ISSN 0379-7112. Available from: https://doi.org/10.1016/j.firesaf.2020.103154

[22] SIME, J. D. An occupant response shelter escape time (ORSET) model. Safety Science [online]. 2001, 38(2), p. 109-125 [accessed 2020-10-11]. ISSN 0925-7535. Available from: https://doi.org/10.1016/S09257535(00)00062-X

[23] GEOERG, P., BLOCK, R., HEISTER, W., HOLL, S., PULM, A., HOFMANN, A. A score regarding the need for assistance - considering pedestrians with impairments in evacuation planning. In: 5th Magdeburg Fire and Explosion Prevention Day: proceedings [online] [accessed 2020-10-11]. 2017. Available from: http://dx.doi. org/10.978.300/0562013

[24] YOUNG, K. Handbook of social psychology. 2. ed. London: Kegan Paul, Trencil Trubner and Co. Ltd., 1957. ISBN-13 978-0710032379.

[25] JONES, E. E., GERARD, H. B. Foundations of social psychology. New York - London- Sydney: John Willey and Sons. Inc., 1967. ISBN 0-471-44906-7.

[26] SHERIF, M., SHERIF, C. W. An outline of social psychology. 2. ed. New York: Harper, 1956.

[27] MCCONNELL, N. C., BOYCE, K. E., SHIELDS, J., GALEA, E. R., DAY, R. C., HULSE, L. M. The UK 9/11 evacuation study: analysis of survivors' recognition and response phase in WTC1. Fire Safety Journal [online]. 2010, 45(1), p. 21-34 [accessed 2020-10-11]. ISSN 0379-7112. Available from: https://doi.org/10.1016/j. firesaf.2009.09.001

[28] JEON, G. Y., KIM, J. Y., HONG, W. H., AUGENBROE, G. Evacuation performance of individuals in different visibility conditions. Building and Environment [online]. 2011, 46(5), p. 1094-1103 [accessed 2020-10-11]. ISSN 0360-1323. Available from: https://doi.org/10.1016/j.buildenv.2010.11.010

[29] FAHY, R., PROULX, G. Toward creating a database on delay times to start evacuation and walking speeds for use in evacuation modelling. In: 2nd International Symposium on Human Behaviour in Fire: proceedings [online] [accessed 2020-10-11]. 2001. Available from: https://nrc-publications.canada.ca/eng/view/ accepted/?id=4fef7a5e-f184-408a-b11f-3ffbf2a61ddf

[30] GWYNNE, S., BOYCE, K. Engineering data. In: SFPE Handbook of fire protection engineering. New York, NY: Springer, 2016. ISBN 978-1-4939-2565-0, p. 2429-2551.

[31] GEOERG, P., POLZIN, M. R., SCHUMANN, J., HOLL, S., HOFMANN, A. Small-scale studies on evacuation characteristics of pedestrians with physical, mental or age-related disabilities. In: 3rd European Symposium on Fire Safety Science: proceedings [online] [accessed 2020-10-11]. 2018. Available from: http://juser.fz-juelich.de/ $\mathrm{record} / 858301$

[32] GEOERG, P., SCHUMANN, J., HOLL, S., BOTLES, M., HOFMANN, A. The influence of individual impairments in crowd dynamics. Fire and Materials [online]. 2020, 2 [accessed 2020-10-11]. ISSN 1099-1018. Available from: https://doi.org/10.1002/fam.2789 
[33] KONNECKE, R., SCHNEIDER, V. Evacuation from underground railway stations - available and required safe egress time for different station types and general evaluation criteria. In: Pedestrian and Evacuation Dynamics 2005: proceedings. Berlin: Springer, 2007. ISBN 978-3-540-47064-9, p. 363-368.

[34] TISSERA, P. C., CASTRO, A., PRINTISTA, A. M., LUQUE, E. Evacuation simulation supporting high level behaviour-based agents. Procedia Computer Science [online]. 2013, 18(2013), p. 1495-1504 [accessed 2020-10-11]. ISSN 1877-0509. Available from: https://doi.org/10.1016/j.procs.2013.05.317

[35] BURSTEDDE, C., KLAUCK, K., SCHADSCHNEIDER, A., ZITTARTZ, J. Simulation of pedestrian dynamics using a two-dimensional cellular automaton. Physica A: Statistical Mechanics and its Applications [online]. 2001, 295(3-4), p. 507-525 [accessed 2020-10-11]. ISSN 0378-4371. Available from: https://doi.org/10.1016/S03784371(01)00141-8

[36] CABOVA, K., APELTAUER, T., OKRINOVA, P., WALD, F. Application of fire and evacuation models in evaluation of fire safety in railway tunnels. In: Building up Efficient and Sustainable Transport Infrastructure 2017: proceedings. Vol. 236. Materials Science and Engineering. 2017. ISSN 1757-8981.

[37] MOZER, V., OSVALD, A., LOVECEK, T., FANFAROVA, A., VRABLOVA, L. Fire safety in tunnels forming part of critical infrastructure. In: International Carnahan Conference on Security Technology ICCST: proceedings. Vol. 2013. Montreal, QC, Canada: Institute of Electrical and Electronics Engineers Inc., 2013. ISBN 978-147990889-9.

[38] ZHAO, X., LOVREGLIO, R., NILSSON, D. Modelling and interpreting pre-evacuation decision-making using machine learning. Automation in Construction [online]. 2020, 113, 103140 [accessed 2020-10-11]. ISSN 0926-5805. Available from: https://doi.org/10.1016/j.autcon.2020.103140

[39] KULIGOWSKI, E. D. Modeling human behavior during building fires. National Institute of Standards and Technology - Technical Note 1619 [online] [accessed 2020-10-11]. 2008. Available from: http://citeseerx.ist.psu. edu/viewdoc/download?doi=10.1.1.462.3209\&rep=rep1\&type=pdf

[40] LOVREGLIO, R., RONCHI, E., NILSSON, D. A model of the decision-making process during pre-evacuation. Fire Safety Journal [online]. 2015, 78, p. 168-179 [accessed 2020-10-11]. ISSN 0379-7112. Available from: https://doi.org/10.1016/j.firesaf.2015.07.001

[41] VORST, H. C. M. Evacuation models and disaster psychology. Procedia Engineering [online]. 2010, 3, p. 15-21 [accessed 2020-10-11]. ISSN 1877-7058. Available from: https://doi.org/10.1016/j.proeng.2010.07.004

[42] KHOLSHEVNIKOV, V. V., SHIELDS, T. J., BOYCE, K. E., SAMOSHIN, D. A. Recent developments in pedestrian flow theory and research in Russia. Fire Safety Journal [online]. 2008, 43(2), p. 108-118 [accessed 2020-10-11]. ISSN 0379-7112. Available from: https://doi.org/10.1016/j.firesaf.2007.05.005

[43] PAN, X., HAN, CH. S., DAUBER, K., LAW, K. H. Human and social behavior in computational modeling and analysis of egress. Automation in Construction [online]. 2006, 15(4), p. 448-461 [accessed 2020-10-11]. ISSN 0926-5805. Available from: https://doi.org/10.1016/j.autcon.2005.06.006

[44] VERWEY, W. B. Theory of psychological functions and cognitive ergonomics: connected? (in Dutch). Tijdschrift voor Ergonomie. 2004, 29(2), p. 4-9. ISSN 0921-4348

[45] PROULX, G. A stress model for people facing a fire. Journal of Environmental Psychology [online]. 1993, 13, p. 137-147 [accessed 2020-10-11]. ISSN 0272-4944. Available from: https://doi.org/10.1016/S02724944(05)80146-X

[46] KULIGOWSKI, E. D., PEACOCK, R. D., HOSKINS, B. L. A review of building evacuation models - technical note 1680 [online] [accessed 2020-10-11]. 2010. Available from: https://tsapps.nist.gov/publication/get_pdf. cfm?pub_id=906951

[47] BRAUN, A., MUSSE, S., OLIVEIRA, L. D., BODMANN, B. Modeling individual behaviors in crowd simulation. In: 16th International Conference on Computer Animation and Social Agents: proceedings. 2003. ISBN 0-7695-1934-2, p. 143-148.

[48] BRUCK, D. The who, what, where and why of waking to fire alarms: a review. Fire Safety Journal [online]. 2001, 36(7), p. 623-639 [accessed 2020-10-11]. ISSN 0379-7112. Available from: https://doi.org/10.1016/S03797112(01)00025-X

[49] SIME, J. D. What is environmental psychology? Texts, content and context. Journal of Environmental Psychology [online]. 1999, 19(2), p. 191-206 [accessed 2020-10-11]. ISSN 0272-4944. Available from: https://doi.org/10.1006/ jevp.1999.0137

[50] GWYNNE, S., GALEA, E. R., OWEN, M., LAWRENCE, P. J., FILIPPIDIS, L. A review of the methodologies used in the computer simulation of evacuation from the built environment. Building and Environment [online]. 1999, 34, p. 741-749 [accessed 2020-10-11]. ISSN 0360-1323. Available from: https://doi.org/10.1016/S03601323(98)00057-2

[51] KULIGOWSKI, E. D. Review of 28 egress models. In: Proceedings of the Workshop on Building Occupant Movement during Fire Emergencies [online] [accessed 2020-10-11]. 2005. p. 66-88. Available from: https://pdfs.semanticscholar.org/89e0/045d33aeaeaebd6be346eaccb9b403193e9a.pdf 
[52] SANTOS, G., AGUIRRE, B. E. A critical review of emergency evacuation simulation models. In: Proceedings of the Workshop on Building Occupant Movement during Fire Emergencies [online] [accessed 2020-10-11]. 2005. p. 25-50. Available from: https://pdfs.semanticscholar.org/89e0/045d33aeaeaebd6be346eaccb9b403193e9a. pdf

[53] PELECHANO, N., MALKAWI, A. Evacuation simulation models: challenges in modeling high rise building evacuation with cellular automata approaches. Automation in Construction [online]. 2008, 17(4), p. 377-385 [accessed 2020-10-11]. ISSN 0926-5805. Available from: https://doi.org/10.1016/j.autcon.2007.06.005

[54] KULIGOWSKI, E. D. Predicting human behavior during fires. Fire Technology [online]. 2013, 49, p. 101-120 [accessed 2020-10-11]. ISSN 0015-2684, eISSN 1572-8099. Available from: https://doi.org/10.1007/s10694-0110245-6

[55] GEOERG, P., BERCHTOLD, F., GWYNNE, S. M. V., BOYCE, K. E., HOLL, S., HOFMANN, A. Engineering egress data considering pedestrians with reduced mobility. Fire and Materials [online]. 2019, 39(2), p. 759-781 [accessed 2020-10-11]. ISSN 1099-1018. Available from: https://doi.org/10.1002/fam.2736

[56] GEOERG, P., HOFMANN, B. A., PULM, A. Evacuation dynamics under consideration of vulnerable pedestrian groups. In: 14th International Fire Science and Engineering Conference: proceedings. Vol. 1. London: Royal Holloway College, 2016. ISBN 978-0-9933933-1-0.

[57] KULIGOWSKI, E. D., GWYNNE, S. M. V. The need for behavioral theory in evacuation modeling. In: Pedestrian and Evacuation Dynamics 2008: proceedings. Berlin: Springer, 2010. ISBN 978-3-642-04504-2, p. 721-732.

[58] APELTAUER, T., HROMADA, M., KOTKOVA, D. Risk analysis of the Prague main railway station as a soft target in different attack scenarios (in Czech). Brno: Brno University of Technology, 2020.

[59] REHAK, D., SLIVKOVA, S., PITTNER, R., DVORAK, Z. Integral approach to assessing the criticality of railway infrastructure elements. International Journal of Critical Infrastructures [online]. 2020, 16(2), p. 107-129 [accessed 2020-10-11]. ISSN 1475-3219, eISSN 1741-8038. Available from: https://doi.org/10.1504/ IJCIS.2020.107256

[60] REHAK, D., NOVOTNY, P. Bases for modeling the impacts of the critical infrastructure silure. Chemical Engineeging Transactions [online]. 2016, 53, p. 91-96 [accessed 2020-10-11]. ISSN 2283-9216. Available from: https://doi.org/10.3303/CET1653016

[61] LEITNER, B., REHAK, D., KERSYS, R. The new procedure for identification of infrastructure elements significance in sub-sector railway transport. Communications - Scientific Letters of the University of Zilina [online]. 2018, 20(2), p. 41-48 [accessed 2020-10-11]. ISSN 1335-4205, eISSN 2585-7878. Available from: http://komunikacie.uniza.sk/index.php/communications/article/view/86

[62] CSN 73 0802: Fire protection of buildings - non-industrial buildings (in Czech). Prague: Office for Technical Standardization, Metrology and State Testing, 2009.

[63] MAWSON, A. R. Understanding mass panic and other collective responses to threat and disaster. Psychiatry [online]. 2005, 68(2), p. 95-113 [accessed 2020-10-11]. ISSN 0033-2747, eISSN 1943-281X. Available from: https://doi.org/10.1521/psyc.2005.68.2.95

[64] LOVECEK, T., Present and future ways of physical property protection. Communications - Scientific Letters of the University of Zilina [online]. 2008, 10(1), p. 35-39 [accessed 2020-10-11]. ISSN 1335-4205, eISSN 2585-7878. Available from: http://komunikacie.uniza.sk/index.php/communications/article/view/1028

[65] SIMAK, L., RISTVEJ, J. The present status of creating the security system of the Slovak Republic after entering the European Union. Journal of Homeland Security and Emergency Management [online]. 2009, 6(1), 20 [accessed 2020-10-11]. ISSN 1547-7355. Available from: https://doi.org/10.2202/1547-7355.1443

[66] ZAGORECKI, A., RISTVEJ, J., COMFORT, L. K., LOVECEK, T. Executive dashboard systems for emergency management. Communications - Scientific Letters of the University of Zilina [online]. 2012, 14(2), p. 82-89 [accessed 2020-10-11]. ISSN 1335-4205, eISSN 2585-7878. Available from: http://komunikacie.uniza.sk/index. $\mathrm{php} / \mathrm{communications/article/view/751}$ 